\title{
A Response to Penders: The Disvalue of Vagueness in Authorship
}

\author{
David Shaw
}

Received: 19 August 2016/Accepted: 15 September 2016/Published online: 15 February 2017

(C) Journal of Bioethical Inquiry Pty Ltd. 2017

Keywords Authorship · Tinkering · Credit . Organization of science $\cdot$ Reward infrastructures . Interdisciplinarity

I thank Dr Penders for his thoughtful response to my article on vagueness in authorship. We appear to be more in agreement than disagreement, but I will focus on the latter here. There appears to be some dissonance in Dr Pender's arguments. He argues both that "there lies value in vagueness" and that "clarity with respect to contributions and the credit and responsibility that ought to come with them, is to be applauded" (Penders 2017, I2). Is it to be applauded falsely, because of the purported value of vagueness? It is somewhat paradoxical to claim that clarity and vagueness are both highly valuable, given their incompatibility.

Dr Penders also argues that "adding contribution statements is unlikely to change authorship designation practices since it does not change the (scientific) process that leads to the publication" (Penders 2017, $[[3$ ). However, this claim appears to be premised on the false assumption that authorship lists should continue to be published alongside contributorship lists. While this is what some journals are

D. Shaw $(\bowtie)$

Institute for Biomedical Ethics, University of Basel,

Bernoullistrasse 28, 4056 Basel, Switzerland

e-mail: david.shaw@unibas.ch

Department of Health, Ethics and Society, CAPHRI Research Institute, Maastricht University, Maastricht, the Netherlands currently doing as a compromise, I favour total abandonment of traditional author lists, which would certainly change authorship designation practices.

I entirely agree that contributorship is not for all disciplines; Dr Penders is quite right to point out that this approach would not work in some fields such as particle physics, for example. In my article I was taking aim at practices in biomedicine and the social sciences/humanities. I also concur that it can be difficult to divide labour on a publication-by-publication basis, rather than on a project basis. But vagueness is not the answer to these challenges: clarity is. Dr Penders argues that vagueness is valuable because "it allows political struggles on authorship to settle locally" (Penders 2017, I10). It is sometimes true that vagueness enables useful compromise between researchers, as I mentioned in my article. But in most cases, vagueness infects and distorts scientific discourse because it promotes ambiguity between writers and readers - ambiguity that leaves interpretation of facts to the consumer of the research, allowing the original vagueness to affect important decisions about funding, careers, and science. Vagueness might have some limited value from time to time, but the overall cost of vagueness is very high.

Dr David Shaw

\section{References}

Penders, B. 2017. The value of vagueness in the politics of authorship. Journal of Bioethical Inquiry 14(1). Doi: 10.1007/s11673-016-9768-3. 